Supplementary Information

\title{
Identification of a small probe that can be conjugated to proteins by proximity labeling
}

Weiping Sun, Yinbo Huo, Yuxuan Mei, Qingtong Zhou, Suwen Zhao, Min Zhuang*

\section{SUPPLEMENTARY METHODS}

Plasmids, Cell Strains, and Media

Protein Expression and Purification

Generation of the Pup Peptide Library

Yeast Surface Labeling

Pup Peptide Library Screening

In vitro PafA labeling assay using purified protein and synthesized peptide

Kinetic assay of DE28 and 4.1

Competition assay

Antibody labeling assay

\section{SUPPLEMENTARY FIGURES}

Supplementary Figure 1. Mapping the short Pup peptide that can interact with PafA.

Supplementary Figure 2. Protein purified for the biochemical assay and yeast surface screening.

Supplementary Figure 3. Validation of the screening strategy.

Supplementary Figure 4. The design of the peptide library.

Supplementary Figure 5. DNA alignment of single clones from the original P22 library shows a diverse library content.

Supplementary Figure 6. Synthesized peptides used for this study.

Supplementary Figure 7. Supplementary data for Figure 2 and Figure 3.

Supplementary Figure 8. Peptide 4.1 generates less complex modifications on protein surface.

Supplementary Figure 9. Supplementary data for Figure 4. 


\section{SUPPLEMENTARY TABLES}

Supplementary Table 1. Oligonucleotides used for P22 library construction.

Supplementary Table 2. Amino acids alignment of single clones from the final round of screening compared with wild type P22. 


\section{METHODS}

\section{Plasmids, Cell Strains, and Media}

\section{Bacterial strains and plasmids}

E. Coli strain DH5a was used for molecular cloning and plasmids amplification. E. Coli strain BL21 was used for protein expression and purification. BCCP-PafA and Protein G-PafA were generated by overlapping PCR and sub-cloned into pGEX6p-1 at the BamH1 cloning site using ClonExpress ${ }^{\circledR}$ Ultra One Step Cloning Kit (Vazyme, cat. \# C115-01).

Yeast strains and plasmids

Saccharomyces cerevisiae EBY-100 was used as the host strain for the yeast surface display experiment. The plasmid pYD2 encodes $\beta$-glucosidase gene and an anchor protein a-agglutinin Aga-2 followed with a V5 tag and a GS linker upstream of the multiple cloning sites ${ }^{1}$. Full length PupE(1-64), PupQ(1-64), and the truncated PupE (43-64) were cloned into PYD2 vector between restriction enzyme sites BamH1 and Mlul, respectively.

\section{Media}

LB media or LB plate are used to culture E. Coli. YPD media and plates were used for yeast culture. Yeasts transformed with pYD2 plasmid were cultured in SD-CAA media ( $0.7 \%$ w/v Yeast Nitrogen Base without Amino Acids, 0.5\% w/v Casamino acid, 5.4\% w/v Na2HPO4, 7.4\% w/v NaH2PO4, 10\% w/v glucose) or SD-CAA plate (SD-CAA media with $15 \mathrm{~g} / \mathrm{L}$ Agar). SG-CAA media $(0.7 \%$ w/v Yeast Nitrogen Base without Amino Acids, 0.5\% w/v Casamino acid, 5.4\% w/v Na2HPO4, 7.4\% w/v NaH2PO4, 10\% w/v galactose) were used to induce Aga-2 fused protein expression.

\section{Protein Expression and Purification}

pGEX6p-PafA and pGEX6p-BCCP-PafA were transformed into BL21, respectively. The cells grew at $37^{\circ} \mathrm{C}$ in LB media with $200 \mu \mathrm{g} / \mathrm{ml}$ ampicillin. The protein expression was induced with 0.6 $\mu \mathrm{M}$ IPTG once the culture $\mathrm{OD}_{600}$ reached $0.6-0.8$, then allowed to grow at $18{ }^{\circ} \mathrm{C}$ overnight. For BCCP-PafA expression, $50 \mu \mathrm{M}$ biotin was supplemented in LB 
media. For each protein, $1 \mathrm{~L}$ culture of cells was harvested and lysed in $20 \mathrm{ml}$ lysis buffer (50 mM Tris 8.0, $200 \mathrm{mM} \mathrm{NaCl}, 5 \mathrm{mM}$ DTT) using cell disruptor. The lysate was incubated with $500 \mu \mathrm{l} \mathrm{GST}$ agarose at $4{ }^{\circ} \mathrm{C}$ for $60 \mathrm{~min}$. The beads were washed three times before the target protein was eluted with elution buffer (150 mM Tris 8.0, $200 \mathrm{mM}$ $\mathrm{NaCl}, 5 \mathrm{mM}$ DTT, $3 \mathrm{mg} / \mathrm{ml} \mathrm{GSH}$ ). GST tag was cleaved off the target protein by the addition of PreScission Protease to the eluted protein and incubated at $4{ }^{\circ} \mathrm{C}$ overnight. GST was further removed by gel filtration chromatography using SD200 column (GE healthcare, cat. \# 28990944).

\section{Generation of the Pup Peptide Library}

A library of Pup mutants was generated by two-step PCR. Two primers were ordered from GENEWIZ with following sequences: forward primer 5'-

CGGCGGATCCATCGACGGCCTGCTCGAAAACAAC, reverse primer 5'GGCCGCCTATTCACCACCTTTCTGAACGTAAGAACGAACGAATTCCTCCGCGTTGTT

TTCGAGCAGGCCG. Underlined nucleotides were synthesized from mixtures containing $70 \%$ of primary base, with $10 \%$ of each of the other bases (supplementary table 1).

First round of PCR was to anneal the two primers to generate the library DNA. $100 \mu \mathrm{M}$ forward primer $(3.5 \mu \mathrm{l})$ and $100 \mu \mathrm{M}$ reverse primer $(3.5 \mu \mathrm{l})$ was added to a PCR reaction mixture and annealed at $72{ }^{\circ} \mathrm{C}, 23 \mathrm{~min}$ for 10 cycles. The double strand DNA was purified by gel extraction (MN, cat. \# 740609). For the second round of PCR, the library DNA was extended and amplified using following primers: Library forward primer 5'-

CTAACCCTCTTCTCGGTCTCGATTCTACGGAGAACCTGTACTTCCAGAGCGGCGGAT CCATCGACGG-3', library reverse primer 5'GATCAGCGGGTTTAAACTCAATGGTGATGGTGATGATGACCGGTACGCGTGGCCGC CTATTCACCACC-3'. Each of the primer contains 50 nucleotides overlapping with the recombination sites on pYD2, which was linearized with two restriction enzymes BamH1 and Mlul1. $1 \mu \mathrm{g}$ library DNA and $1 \mu \mathrm{g}$ linearized vector are transformed into $5 \times 10^{7}$ EBY-100 fresh competent cells by electroporation in transfer buffer (1 M sorbitol with 1 $\mathrm{mM} \mathrm{CaCl}_{2}$ ) with BioRad Gene Pulser at $1500 \mathrm{~V}, 25 \mathrm{uF}, 4.0 \sim 5.0 \mathrm{~ms}$. The cells were 
allowed to rest at room temperature for 1 hour before being resuspended in $100 \mathrm{ml} \mathrm{SD}$ CAA media. $100 \mu \mathrm{l}$ of $10 \mathrm{x}, 100 \mathrm{x}, 1000 \mathrm{x}$ dilutions of transformed yeasts were plated on SD-CAA plates and grew for 2-3 days for library size estimation. The library was amplified and stored in $-80{ }^{\circ} \mathrm{C}$.

\section{Yeast Surface Labeling}

pYD2-Pup plasmid was transformed into EBY-100 by electroporation. The cells were plated and grown on SD-CAA plate for 2-3 days. A single clone was picked up and cultured in SD-CAA media supplemented with 50 units $/ \mathrm{ml}$ penicillin and $50 \mu \mathrm{g} / \mathrm{ml}$ streptomycin at $30{ }^{\circ} \mathrm{C}$, shaking at $250 \mathrm{rpm}$ overnight. The culture media was changed to SG-CAA to induce peptide expression when cells grow in the logarithmic phase $\left(\mathrm{OD}_{600}=2 \sim 5\right)$. After 24 hours induction, $10^{8}$ cells were harvested, washed with PBS for three times at $4{ }^{\circ} \mathrm{C}$, and resuspended in $170 \mu \mathrm{PBS}$ with $0.1 \%$ BSA . $10 \mu \mathrm{l}$ purified BCCP-PafA (final concentration is $2 \mu \mathrm{M}$ ), $20 \mu \mathrm{l} 10 \times$ reaction buffer (final concentration is $10 \mathrm{mM}$ ATP, $15 \mathrm{mM} \mathrm{MgCl}, 20 \mathrm{mM}$ Tris 8.0), were added to the suspended yeasts to set up the reaction at $30{ }^{\circ} \mathrm{C}$ for $1 \mathrm{~h}$. Gently tap the reaction tube every $10 \mathrm{~min}$ to prevent yeasts from settling down to the bottom of the tube. Wash cells with PBS for three times to stop the reaction and remove unbound proteins. $10^{7}$ cells were used for each fluorescent staining. Yeasts were first resuspended in $100 \mu \mathrm{l} \mathrm{PBSA}, 0.5 \mu \mathrm{l}$ anti-V5 antibody (Abcam, cat. \# ab27671 ) was added to incubate on ice for $25 \mathrm{~min}$. Wash yeasts for three times with $500 \mu \mathrm{l}$ PBS, add $100 \mu \mathrm{l}$ PBSA and $1 \mu \mathrm{l}$ goat anti-mouse IgG $(\mathrm{H}+\mathrm{L})$ cross-adsorbed secondary antibody conjugate Alexa Fluor 488 (Life, cat. \# A11001) and $1 \mu$ Alexa Fluor 647-conjugated streptavidin (Jackson, cat. \# 016-600-084), incubate on ice under dark for $25 \mathrm{~min}$. Wash thoroughly with PBS for 3 times, analyze yeast surface fluorescence by FACS.

\section{Pup Peptide Library Screening}

$1 \times 10^{8}$ yeast original library cells were recovered and grow on SD-CAA media at $30{ }^{\circ} \mathrm{C}$ until $O_{600}$ reach 2-5. Yeasts were centrifuged and resuspended with SG-CAA to make $\mathrm{OD}_{600}=1$. Yeasts were further grown at $25^{\circ} \mathrm{C}$ for $24 \mathrm{hrs}$ before being harvested for 
screening. For the first round of screening, $1 \times 10^{8}$ cells were harvested and washed with $1 \mathrm{x}$ PBS for 3 times, then cells were resuspended with PBSA to a final volume of $160 \mu \mathrm{l}$, $20 \mu \mathrm{l}$ purified BCCP-PafA (final concentration is $4 \mu \mathrm{M}$ ) and $20 \mu \mathrm{l} 10 \mathrm{x}$ reaction buffer were added to the solution and incubated with cells for 60 minutes at $30{ }^{\circ} \mathrm{C}$. Cells were washed and retained, The highest double positive cells were isolated and grow to saturation. To increase selection pressure, the concentration of BCCP-PafA was reduced from an initial $4 \mu \mathrm{M}$ in the first round to $0.4 \mu \mathrm{M}$ in the final round of screening. The reaction time was shortened during each round of selection from 60 minutes to 20 minutes.

\section{In vitro PafA labeling assay using purified protein and synthesized peptide}

$4 \mu \mathrm{l}$ of $10 \mu \mathrm{M}$ substrate (full length BCCP-PupE protein, bio-QE35, bio-DE28, or P22), 4 $\mu \mathrm{l}$ of $5 \mu \mathrm{M}$ GST-PafA, $28 \mu \mathrm{l} \mathrm{H}_{2} \mathrm{O}$, and $4 \mu \mathrm{l}$ of the $10 \mathrm{x}$ reaction buffer containing $200 \mathrm{mM}$ Tris8.0, $100 \mathrm{mM} \mathrm{ATP,} \mathrm{and} 150 \mathrm{mM} \mathrm{Mg}^{2+}$ were mixed and incubated at room temperature for $10 \mathrm{~min}$ to allow the in vitro self labeling of GST-PafA The reaction was stopped by adding $40 \mu \mathrm{l} 3 \times$ SDS protein loading buffer. Western blot was performed with streptavidin-HRP(Cell signaling, cat. \# 3999S) or anti-GST antibody (1: 3000, Cell signaling, Cat. \# 2622S).

All peptides were synthesized from Kanglong Biotech and dissolved in $20 \mathrm{mM}$ Tris 8.0 to a final concentration of $2 \mathrm{mM}$, adjusting $\mathrm{PH}$ to $7 \sim 8$ with $\mathrm{NaOH}$, peptides were aliquoted and stored in $-80^{\circ} \mathrm{C}$ before use.

\section{Kinetic assay of DE28 and 4.1}

For the kinetic assay performed with FITC-DE28, $10 \mu \mathrm{l}$ of $1 \mu \mathrm{M}$ GST-PafA was mixed with $4 \mu \mathrm{l} 10 \mathrm{x}$ reaction buffer, $24 \mu \mathrm{l}$ water and $2 \mu \mathrm{l}$ of substrate for the final FITC-DE28 concentration of $0.7812,0.156,0.312,0.625,1.25,5,10,15$, or $20 \mu \mathrm{M}$. Each reaction was $40 \mu \mathrm{l}$ in total. At each time point $(20 \mathrm{~s}, 40 \mathrm{~s}$, and $60 \mathrm{~s}), 10 \mu \mathrm{l}$ reaction mixture was removed and added to $10 \mu \mathrm{l} 3 \times$ SDS protein loading buffer to stop the reaction. All samples were loaded on 4-20\% pre-cast Express Plus SDS-PAGE gels(Genscript, cat, \# 
M42015C) and FITC fluorescence was detected using typhoon FLA 9500. For the kinetic assay performed with FITC-4.1, similar experiments were set up but with slightly different peptide concentrations. The final FITC-4.1 concentrations in the reaction were $0.156,0.312,0.625,1,1.25,2.5,5$, and $10 \mu \mathrm{M}$ respectively.

\section{Competition assay}

FITC-P28 was considered as a natural substrate of PafA ligase, P22 and 4.1 were regarded as the inhibitors to compete the active site with DE28. In vitro PafA labeling assays were set up as described above. The competitive peptides were added to each reaction to reach the final concentrations at $200,150,100,75,50,25,20,12.5,6.25$, $3.125,1.560 \mu \mathrm{M}$ for biotin-4.1, and 700, 500, 350, 175, 100, 50, 25, 12.5, 6.25, 3.125, $1.56 \mu \mathrm{M}$ for biotin-P22 respectively. The reactions were stopped after $10 \mathrm{~min}$ incubation at room temperature. Samples were loaded on 4-20\% pre-cast Bis-Tris SDS-PAGE and imaged by typhoon FLA 9500.

\section{Antibody labeling assay}

The antibody labeling reactions were set up in a $10 \mu \mathrm{l}$ reaction volume. In a full reaction, the final concentration of Protein G-PafA is $0.5 \mu \mathrm{M}$ while the peptide concentration is $10 \mu \mathrm{M}$. Control lgG (GeneScript, A01007) or anti- $\beta$ actin IgG (Celll Signaling, 3700S) was added to the reaction for a final concentration at $0.5 \mu \mathrm{M}$. The reaction was initiated by the addition of $10 \mathrm{X}$ reaction buffer $(200 \mathrm{mM}$ Tris8.0, $100 \mathrm{mM}$ ATP, and $150 \mathrm{mM} \mathrm{Mg}^{2+}$ ) and allowed to react at room temperature for $50 \mathrm{~min}$ and stopped by diluting immediately in cold $5 \mathrm{ml} 5 \%$ non-fat milk TBS blotting buffer. For the control sample, ATP or anti- $\beta$ actin IgG was omited in the reaction. $25 \mu \mathrm{M}$ free protein $G(P G)$ is added to one of the full reactions after labeling to disrupt the interaction between PG-PafA and the antibody.

\section{REFERENCES}

1. Razai A, Garcia-Rodriguez C, Lou J, et al. Molecular evolution of antibody affinity for sensitive detection of botulinum neurotoxin type A. J Mol Biol. 
2005;351(1):158-169. doi:10.1016/j.jmb.2005.06.003 


\section{Supplementary Figures}

a
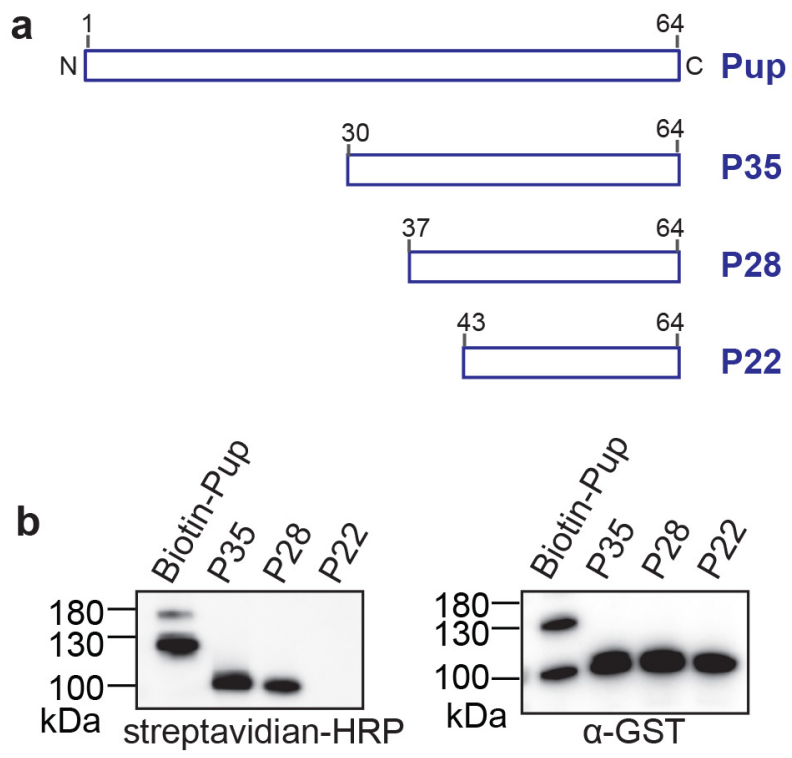

Supplementary Figure 1. Mapping the short Pup peptide that can interact with PafA.

(a) The design of different Pup truncations.

(b) In vitro GST-PafA modification assay with different Pup truncations. $0.5 \mu \mathrm{M}$ purified GST-PafA and $1 \mu \mathrm{M}$ substrate are incubated in the presence of ATP at $37^{\circ} \mathrm{C}$ for 10 min. Biotin is fused to the $\mathrm{N}$ terminus of each truncated peptide. 

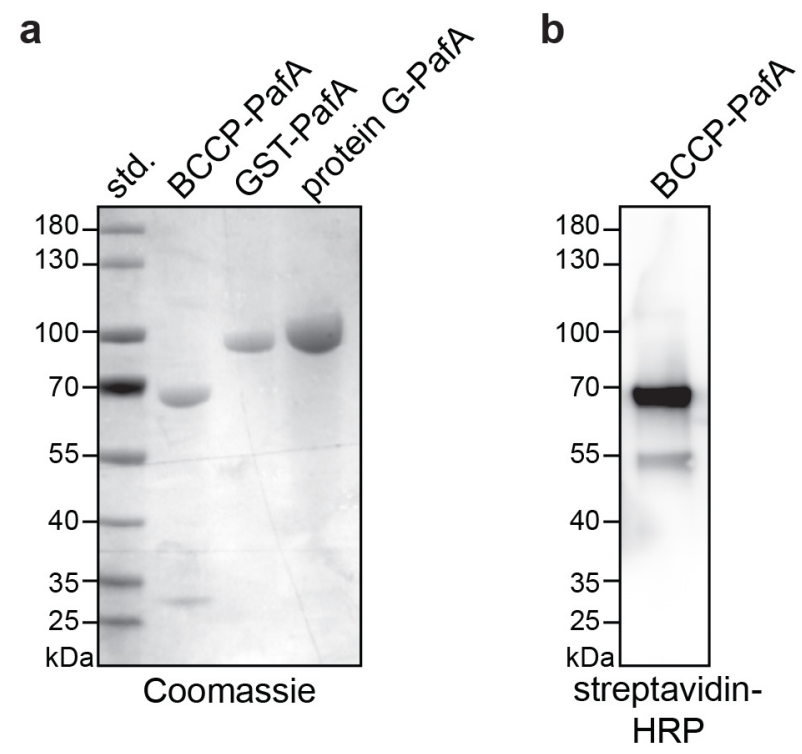

Supplementary Figure 2. Protein purified for the biochemical assay and yeast surface screening.

(a) SDS-PAGE with coomassie staining of BCCP-PafA, GST-PafA and protein G-PafA. All the proteins were expressed in E. Coli and purified through GST pull down. GST tag on BCCP-PafA and protein G-PafA was cleaved off and the target protein was further purified through gel filtration chromatography.

(b) BCCP-PafA is biotin modified. BCCP domain is known to be a biotin carrier domain. Western blot shows that BCCP-PafA used for yeast surface screening contains biotin moiety. 


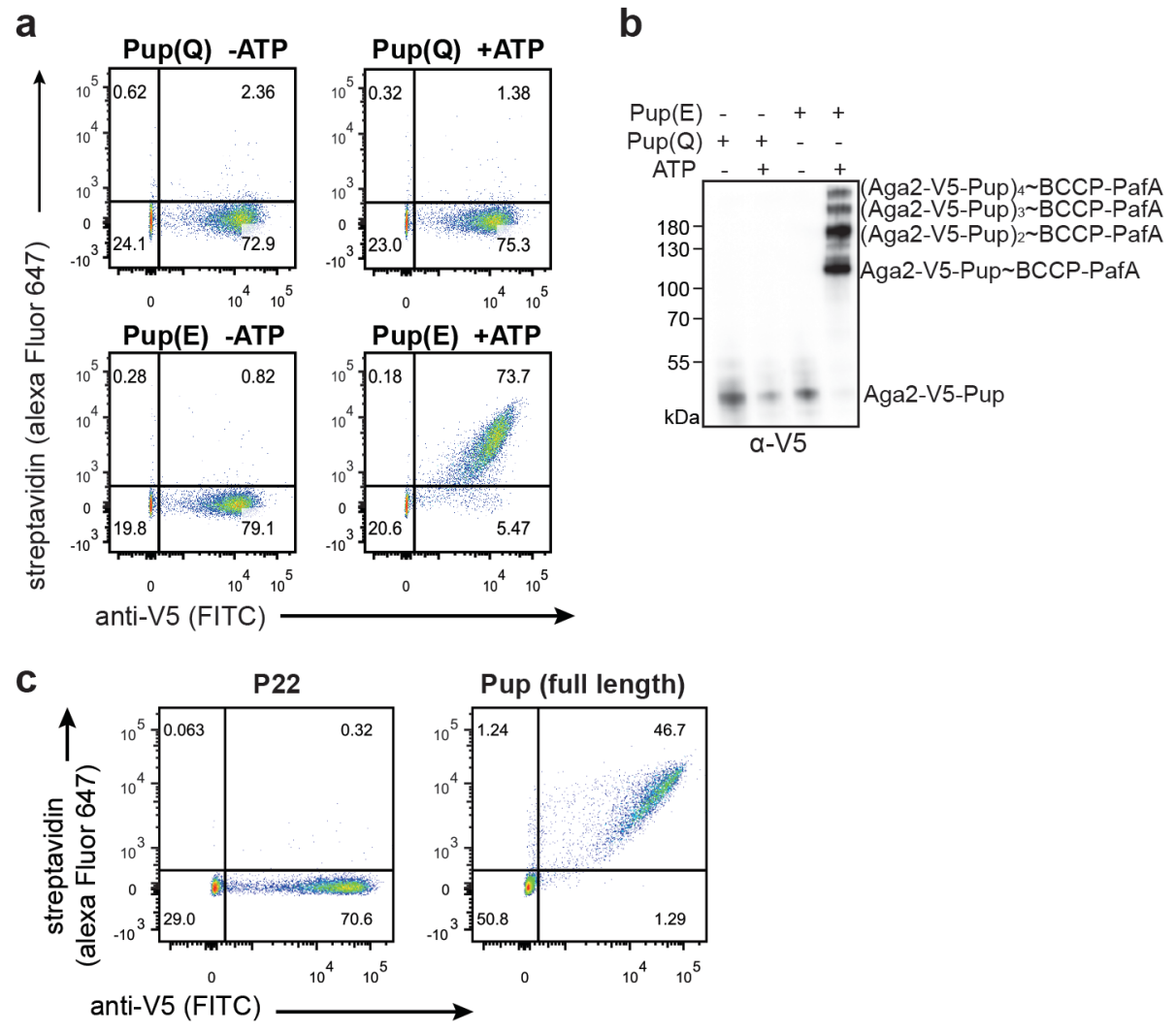

\section{Supplementary Figure 3. Validation of the screening strategy.}

(a) Yeast surface displayed $P u p(E)$ reacts with BCCP-PafA. Pup $(Q)$, which contains a glutamine instead of glutamate at the $C$ terminus of the peptide, was used as the negative control.

(b) Aga2 fused Pup peptide is covalently linked to BCCP-PafA. The western blot shows increased molecular weight of Aga2-V5-Pup in the presence of BCCP-PafA and ATP. Pup $(\mathrm{Q})$ was used as negative control.

(c) The truncated Pup peptide P22 cannot react with PafA. P22 was fused with Aga2 and similar yeast surface labeling experiment was performed with full length Pup. 


\begin{tabular}{|c|c|}
\hline peptide & sequence \\
\hline P22 & 43-IDGLLENNAEEFVRSYVQKGGE-64 \\
\hline P22 library & IDGLLENNXXXXXXXXXXXGGE \\
\hline
\end{tabular}

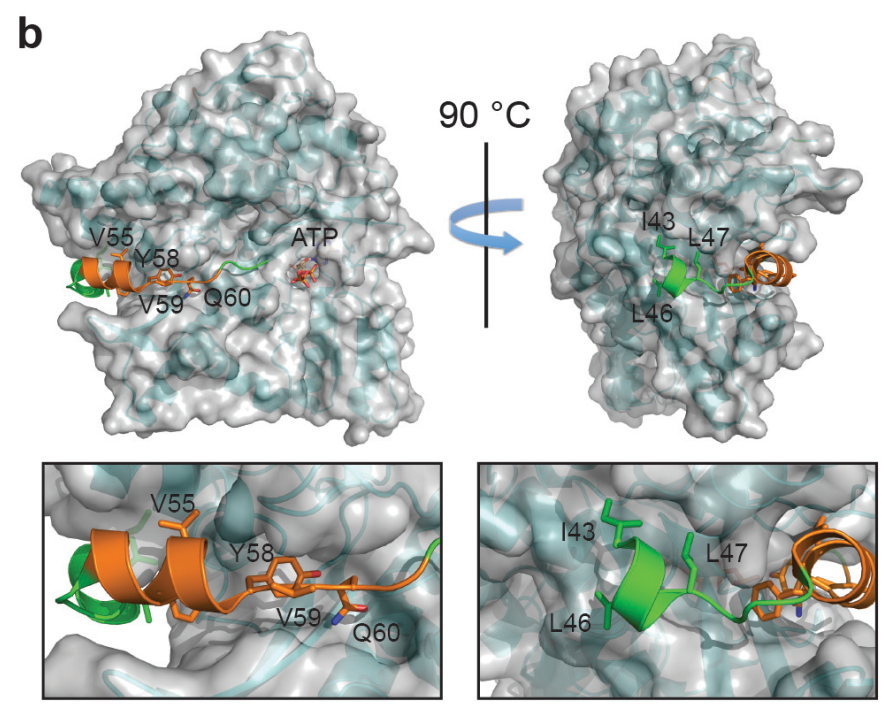

Supplementary Figure 4. The design of the peptide library.

(a) The sequences of wild type P22 and P22 library. The residues shown in green are remained in the library, while the residues in orange are subjected for mutagenesis.

(b) Visualization of the mutated region on the structure of PafA-Pup complex. 


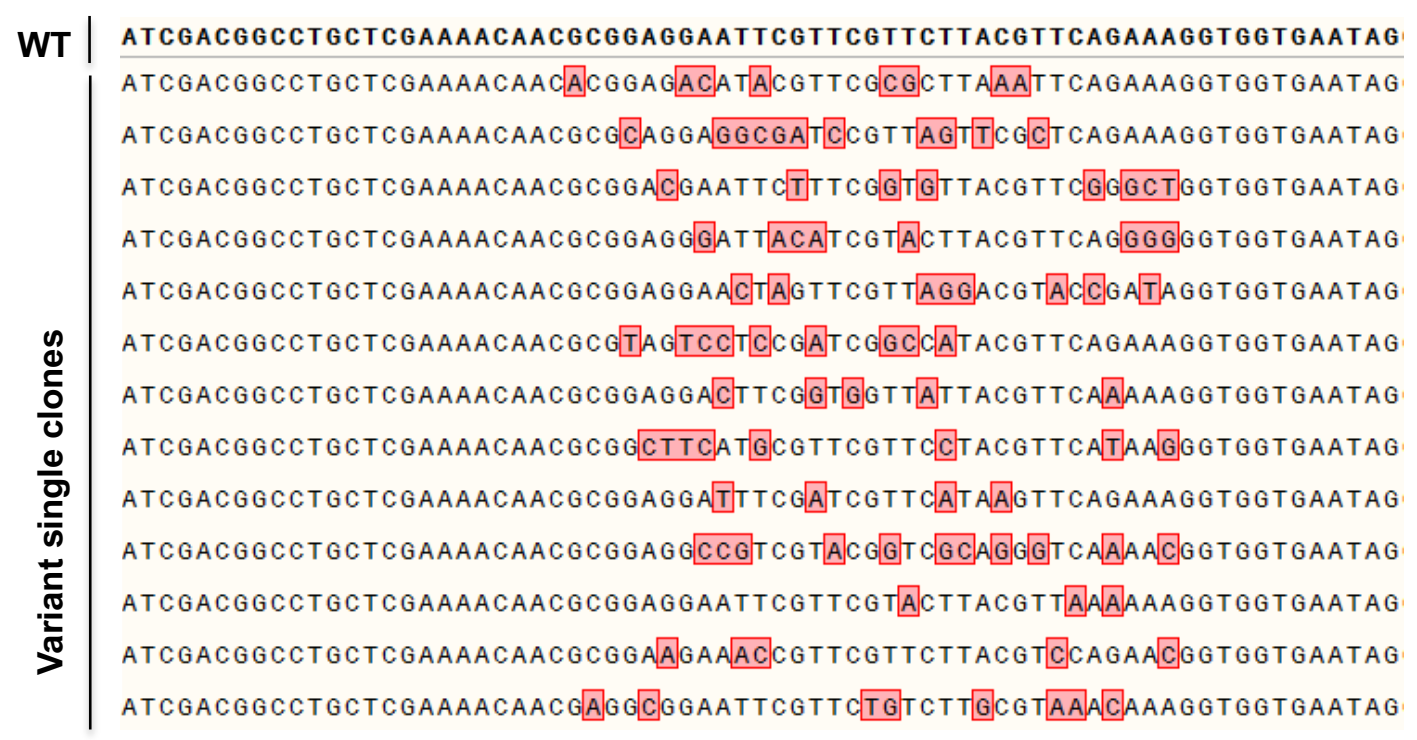

\section{Supplementary Figure 5. DNA alignment of single clones from the original P22 library shows a diverse library content.}


a
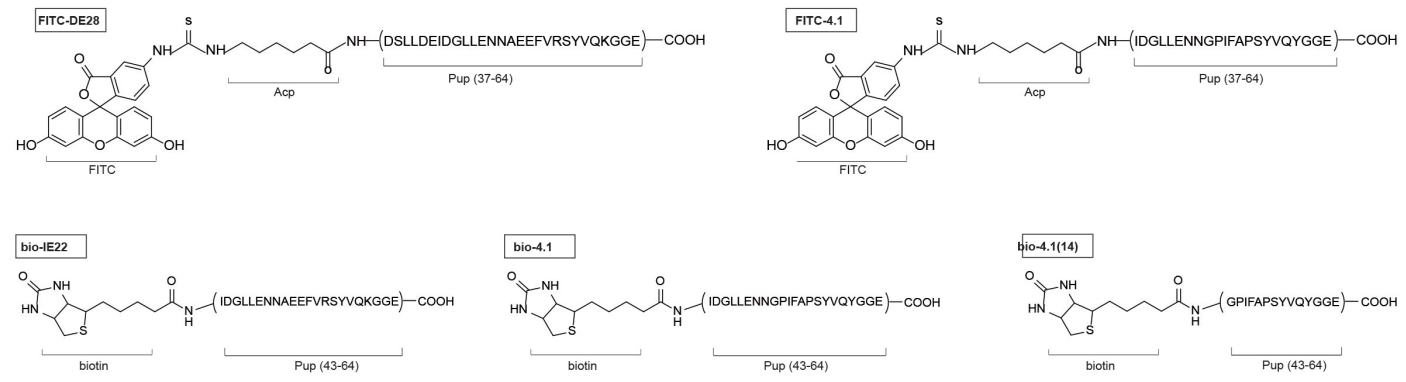

b
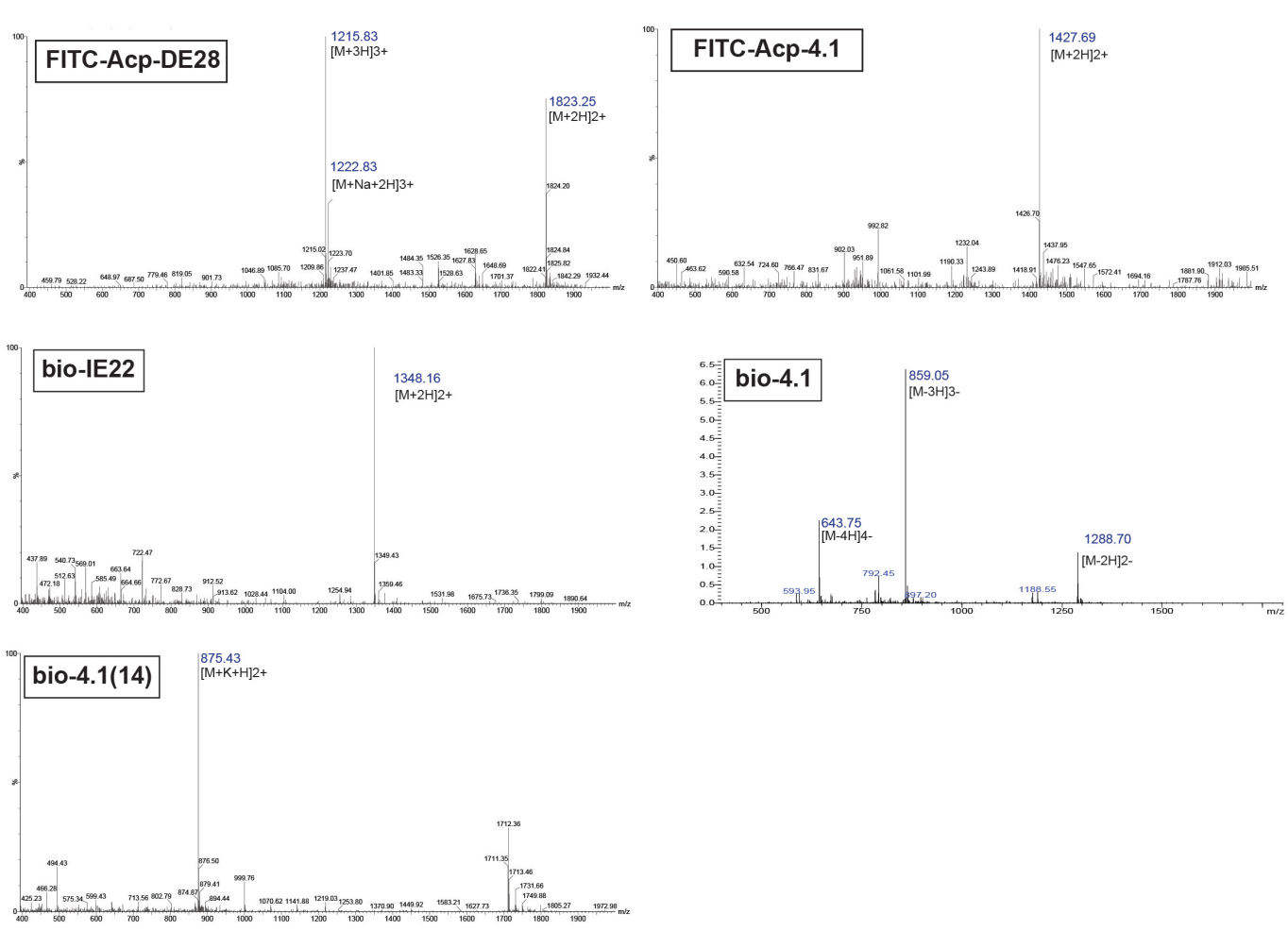

Supplementary Figure 6. Synthesized peptides used for this study.

(a) The structure of each peptide.

(b) Mass spectrometry data for each synthesized peptide. 
a

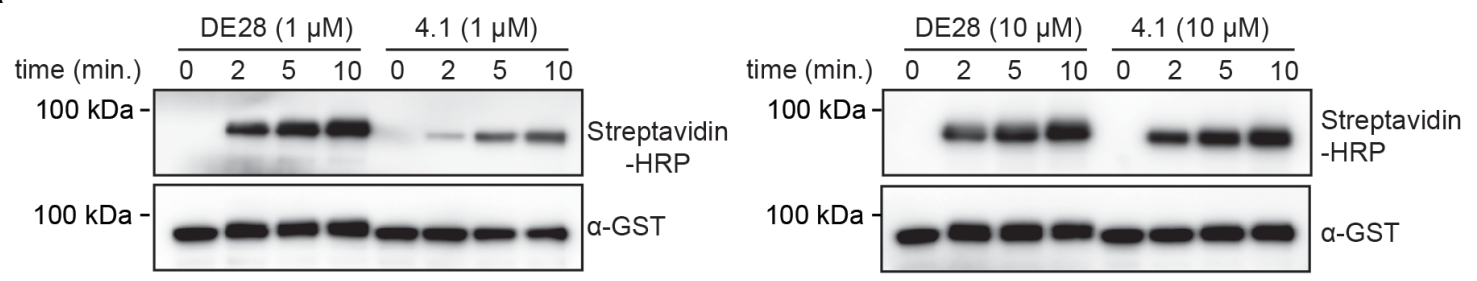

b

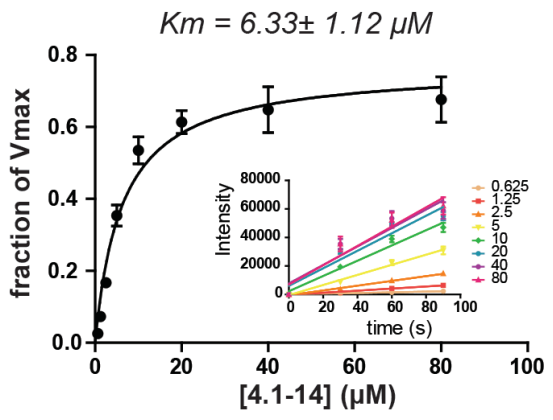

\section{Supplementary Figure 7. Supplementary data for Figure 2 and Figure 3.}

(a) Direct comparsion between DE28 and 4.1 (supplementary to Fig 2). At low peptide concentration near $\mathrm{Km}$ (left), there are slightly less labeling with 4.1 ; at high peptide concentration (right), both peptides work similarly.

(b) Km measurement for peptide 4.1-14 (supplementary to Fig 3). 
a

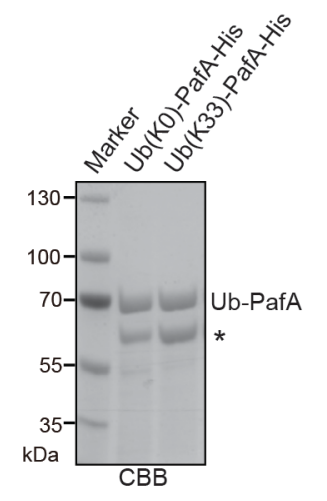

b

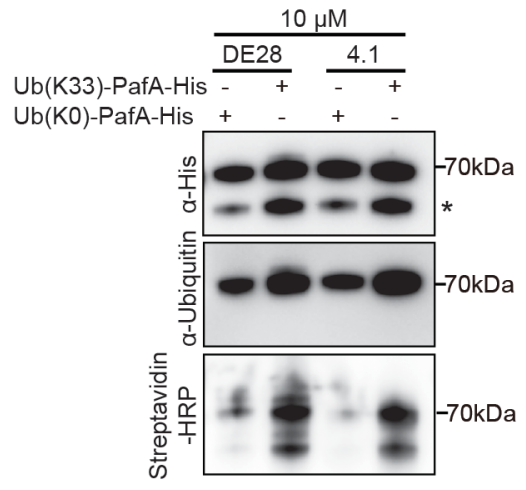

DE28 modification

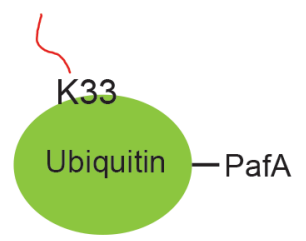

Ub(K33)-PafA-His $\frac{100 \mu \mathrm{M}}{\frac{\mathrm{DE} 28}{-}+\frac{4.1}{-+}}$

$\mathrm{Ub}(\mathrm{K} 33)$-PafA-His

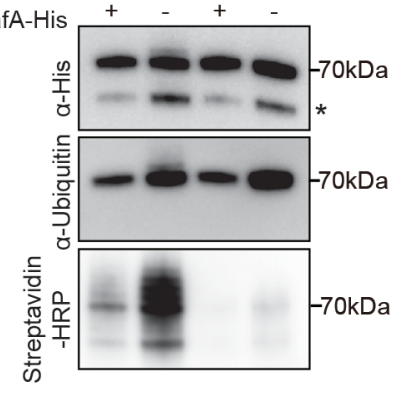

DE28 modification

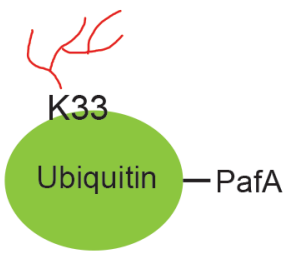

4.1 modification

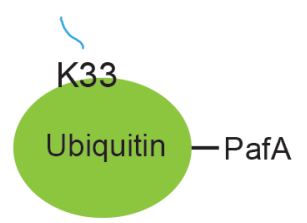

C

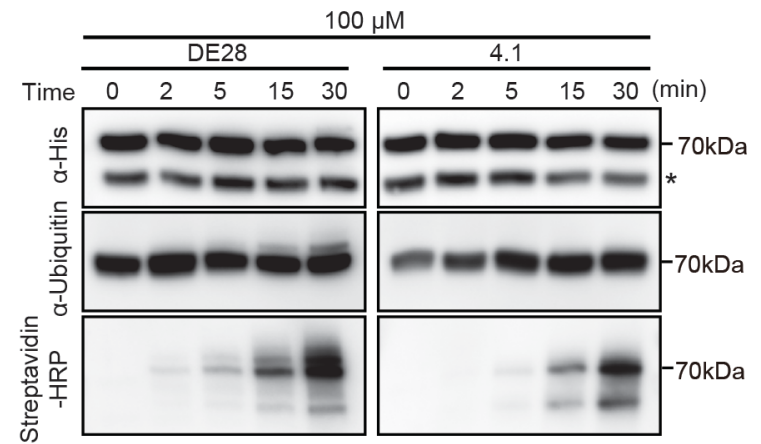

Ub(K33)-PafA-His modification 


\section{Supplementary Figure 8. Peptide 4.1 generates less complex modifications on protein surface.}

(a) The purification of Ub-PafA. All surface Lysines on ubiquitin are mutated to Arginine (K0) or only one Lysine residue are maintain on ubiquitin (K33). Those ubiquitin variants were fused with PafA and purified through the $\mathrm{N}$ terminal His tag. "*” indicates a none specific protein fragment (likely the cleaved protein).

(b) Ubiquitin modification assay with Ub-PafA. Top panel, the reactions were carried out wtih $1 \mu \mathrm{M}$ Ub-PafA and $10 \mu \mathrm{M}$ peptides. His-Ub(K0)-PafA has very weak label background labeling on PafA. Both DE28 and 4.1 has the similar labeling pattern. Bottom panel, the reactions were carried out with $1 \mu \mathrm{M}$ Ub-PafA and $100 \mu \mathrm{M}$ peptides. Extra peptide generates multiple modifications on His-Ub(K33)-PafA with DE28, but not with 4.1. Giving the similar Km for DE28 and 4.1, the result indicates 4.1 labeling can be saturated.

(c) Ubiquitin modification assay with $\mathrm{Ub}(\mathrm{K} 33)$-PafA. The reactions were carried out with $1 \mu \mathrm{M} \mathrm{Ub}(\mathrm{K} 33)-\mathrm{PafA}-\mathrm{His}$ and $100 \mu \mathrm{M}$ peptides at $20^{\circ} \mathrm{C}$. Over time, There are modified Ub(K33)-PafA with higher molecular weight with DE28 but not with 4.1, indicating a more complex modification with DE28. 
a

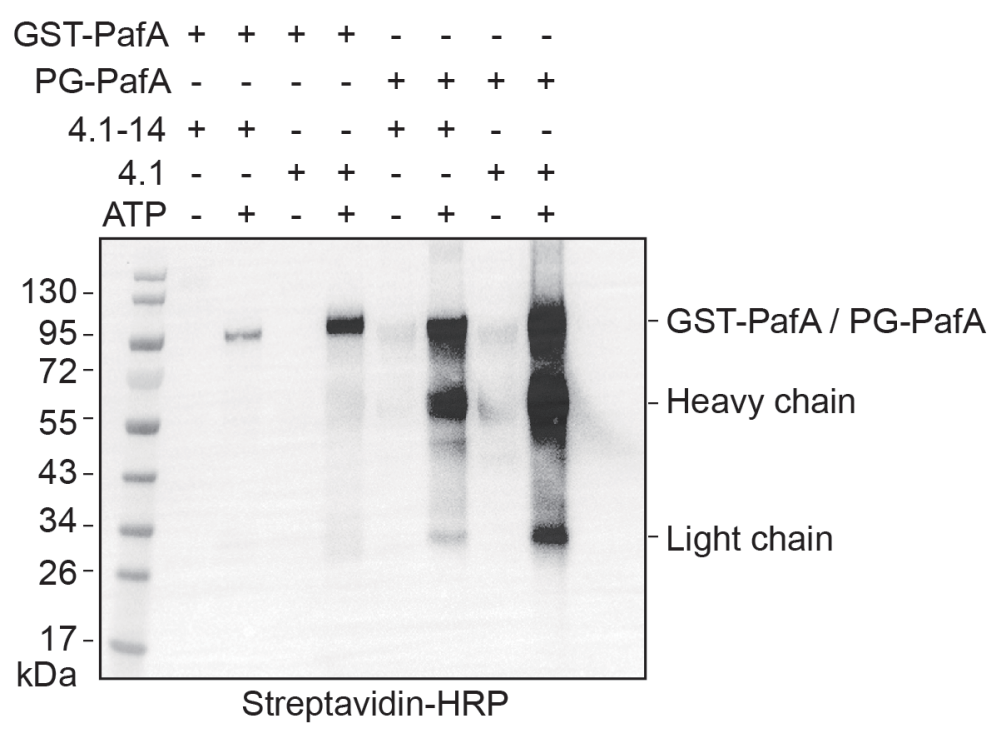

b

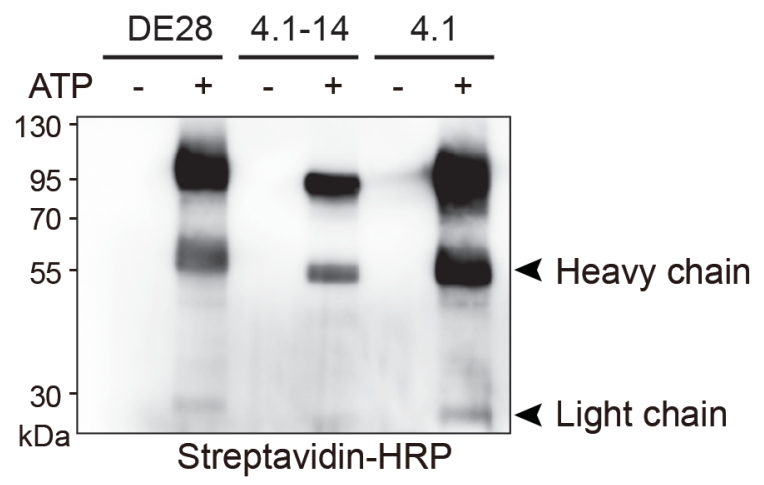

\section{Supplementary Figure 9. Supplementary data for Figure 4.}

(a) Both the heavy chain and light chain of the antibody can be modified by PG-PafA. The labeling reactions were carried out similarly to the experiments in Fig $4 \mathrm{~b}$, but different enzyme/pep ratio was used. In this experiment, $0.1 \mu \mathrm{M}$ PG-PafA and 10 $\mu \mathrm{M}$ peptide were used while in Fig 4b, $0.5 \mu \mathrm{M}$ PG-PafA and $10 \mu \mathrm{M}$ peptide were used.

(b) The labeling pattern for all three peptides are the same. 


\section{Supplementary tables}

Table 1. Oligonucleotides used for P22 library construction.

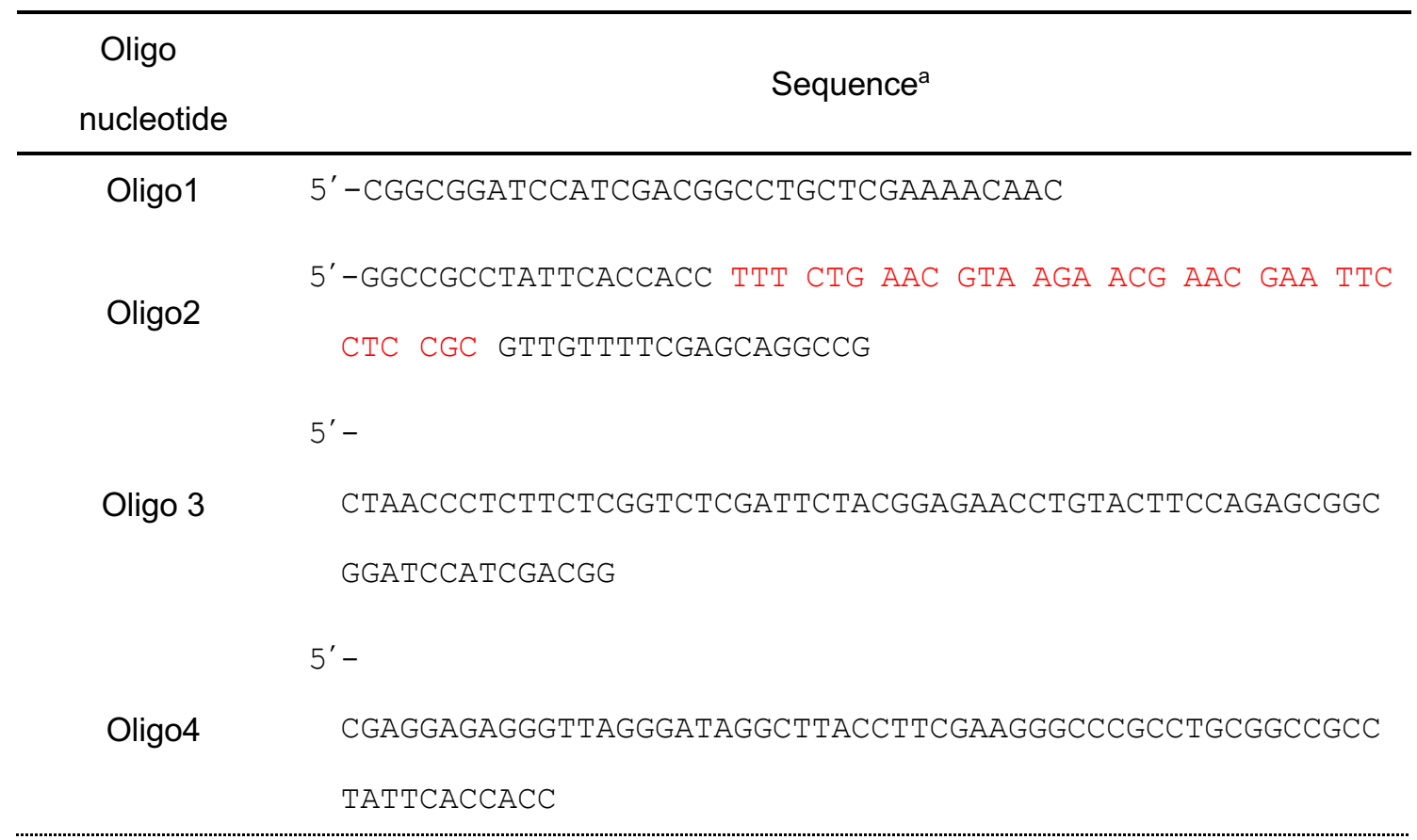

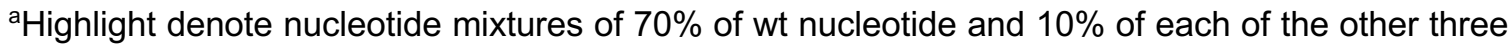
nucleotides. 
Table 2. Amino acids alignment of single clones from the final round of screening compared with wild type P22.

Round Clones P22 variant sequence

43444546474849505152535455565758596061626364

\begin{tabular}{|c|c|c|c|c|c|c|c|c|c|c|c|c|c|c|c|c|c|c|c|c|c|c|c|}
\hline 4 & WT & I & D & G & L & L & $E$ & & & & & & 1 & 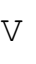 & $\mathrm{R}$ & S & Y & V & ? & K & G & & $\mathrm{E}$ \\
\hline 4 & 4.1 & - & - & - & - & - & - & - & - & $\mathrm{G}$ & ת & $T$ & & & 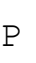 & & & & & Y & & & - \\
\hline 4 & 4.2 & - & - & - & - & - & - & & & $G$ & $\mathrm{E}$ & I & & & P & & & & - & $\mathrm{Y}$ & & & - \\
\hline 4 & 4.3 & - & - & - & - & - & - & & & G & D & $T$ & & & & & & & 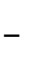 & $\mathrm{V}$ & & & - \\
\hline 4 & 4.4 & - & - & - & - & - & - & & & & & $\mathrm{H}$ & L & & & & 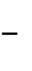 & A & L & . & - & - & - \\
\hline 4 & 4.5 & - & - & - & - & - & - & & & $G$ & $\mathrm{P}$ & I & & & P & & - & & - & & 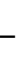 & _ & - \\
\hline 4 & 4.6 & - & - & - & - & - & - & & & G & I & $T$ & 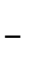 & 7 & D & 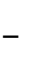 & - & - & - & $\perp$ & 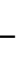 & - & - \\
\hline 4 & 4.7 & - & - & - & - & - & - & & & $\mathrm{G}$ & $\mathrm{F}$ & I & & A & $\mathrm{P}$ & & - & - & - & Y & - & - & - \\
\hline 4 & 4.8 & - & - & - & - & - & - & & & C & P & T & & & & & 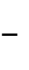 & & - & $\mathrm{V}$ & 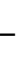 & - & - \\
\hline 4 & 4.9 & - & - & - & - & - & 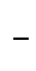 & & 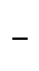 & $G$ & F & $\perp$ & 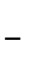 & 21 & $F$ & - & - & - & - & 1 & - & - & - \\
\hline 4 & 4.10 & - & - & - & - & - & & & & $\mathrm{G}$ & $\mathrm{P}$ & I & - & & $\mathrm{P}$ & - & - & - & - & Y & - & - & - \\
\hline 4 & 4.11 & - & - & - & - & - & & & & G & D & $T$ & 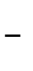 & $\pi$ & ת & 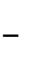 & 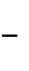 & 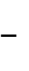 & - & Y & - & 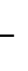 & - \\
\hline 4 & 4.12 & - & - & - & - & - & - & & & $G$ & $\mathrm{P}$ & $\perp$ & - & & r & - & 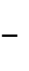 & 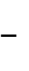 & - & Y & - & - & - \\
\hline 4 & 4.13 & - & - & - & - & & & & & G & $\mathrm{P}$ & I & - & 12 & $\mathrm{P}$ & - & - & - & - & Y & - & - & - \\
\hline 4 & 4.14 & - & - & - & - & & & & & 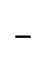 & 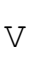 & 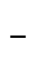 & + & + & . & 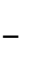 & 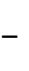 & 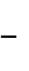 & W & L & - & - & - \\
\hline 4 & 14.15 & - & - & - & - & - & 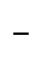 & & & G & $\mathrm{P}$ & I & - & A & $\mathrm{P}$ & - & - & - & - & Y & - & - & - \\
\hline 4 & 4.16 & - & - & - & - & 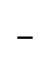 & . & . & 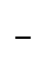 & G & P & I & - & 1 & P & - & - & - & - & Y & - & - & - \\
\hline 4 & 4.17 & - & - & - & - & 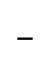 & 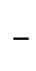 & 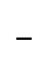 & 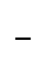 & $\checkmark$ & $F$ & $\perp$ & 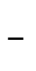 & A & P & - & - & - & - & Y & - & - & - \\
\hline 4 & 4.18 & - & - & - & - & - & - & 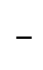 & . & $\mathrm{G}$ & P & I & - & A & P & - & - & - & - & Y & - & - & - \\
\hline 4 & 4.19 & - & - & - & - & - & - & - & - & G & P & I & - & $\mathrm{A}$ & P & - & - & - & - & Y & - & - & - \\
\hline 4 & 4.20 & - & - & - & - & & - & - & - & $P$ & - & G & W & - & - & - & W & F & $\mathrm{H}$ & - & - & - & - \\
\hline
\end{tabular}

